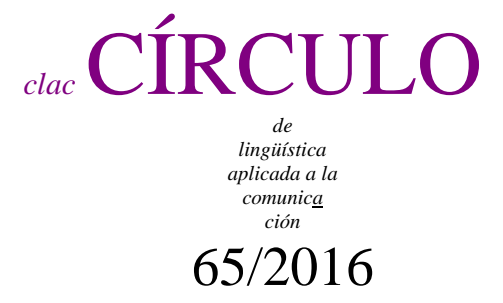

\title{
FIFTH INTERNATIONAL CONFERENCE ON MEANING AND KNOWLEDGE REPRESENTATION
}

\author{
http://www.fungramkb.com/events/2016/cfp.html \\ Universidad de Las Palmas de Gran Canaria \\ Las Palmas de Gran Canaria, July 6, 7 and 8, 2016
}

Abstract submission deadline: March 11, 2016

The Fifth International Conference on Meaning and Knowledge Representation will take place in Las Palmas de Gran Canaria (Spain), July 6, 7 and 8, 2016.

Natural language understanding systems require a knowledge base provided with formal representations reflecting the structure of human beings' cognitive system. Although surface semantics can be sufficient in some other systems, the construction of a robust knowledge base guarantees its use in most natural language processing applications, thus consolidating the concept of resource reuse. This conference deals with meaning and knowledge representation in the context of natural language understanding from the perspective of theoretical linguistics, computational linguistics, cognitive science, knowledge engineering or artificial intelligence.

Published: February 29, 2016

Updated: March 7, 2016

Círculo de Lingüística Aplicada a la Comunicación 65, 366.

http://www.ucm.es/info/circulo/no65/laspalmas.pdf

http://revistas.ucm.es/index.php/CLAC

http://dx.doi.org/10.5209/rev_CLAC.2016.v65.52014 